\section{El derecho de información en medicina curativa y satisfactiva}

\author{
Sr. Editor:
}

A día de hoy, es bien sabido que en el seno de la relación clínica el deber de información del profesional y el derecho del paciente a conocer sus datos implica la transmisión de una información "adecuada". Ahora bien, con base en la legislación sanitaria y la jurisprudencia, es de advertir que el contenido de información al que hace referencia el término "adecuado" varía según el campo de la medicina en el que el profesional desarrolle su actividad: curativa o satisfactiva. Por ello, es recomendable que el facultativo tenga en cuenta la diferenciación apuntada, dado que, el hecho de no transmitir la información en los términos prescritos puede ser interpretado como una intromisión en la autonomía de la voluntad del paciente y ello, puede generar responsabilidad profesional.

Bajo esta premisa, cabe recordar que la medicina curativa atiende a un proceso patológico, de forma que la asistencia está vinculada al estado de salud de la persona $y$, por lo tanto, la intervención es necesaria. En cambio, la medicina satisfactiva es voluntaria y, si bien las actuaciones encuadradas en el concepto son de diversa índole, con carácter general, la persona no presenta dolencia patológica y la intervención se lleva a cabo para alcanzar un resultado pactado ${ }^{1}$.

No obstante lo anterior, la diferencia sustancial entre ambas estriba en la naturaleza de la obligación del facultativo. El profesional, en la medicina curativa, durante el desarrollo de su actividad, habida cuenta de que el objetivo de la prestación sanitaria es la recuperación, mejora o curación del estado de salud del paciente, al ser una finalidad que no puede ser garantizada, la obligación a la hora de efectuar la actuación consiste en el empleo de los medios a su alcance para realizar una buena praxis, con la diligencia debida y según el estado actual de la ciencia. Por lo tanto, la falta de éxito no es sinónimo de resarcimiento o reparación de daños, dado que la obligación del profesional es de medios. Sin embargo, en la medicina satisfactiva, la naturaleza de la obligación es de resultado, por ser voluntaria y no necesaria².

Dicho esto, la clave a la hora de perfilar el contenido considerado esencial que debe ser transmitido en uno y otro campo radica en la diversidad de grados distintos en el que debe ser precisada la información ${ }^{3}$, debiendo contemplar, en este caso, la medicina de carácter satisfactiva una información más amplia y exhaustiva que en la medicina de carácter curativo ${ }^{4}$. Así pues, el deber de información se agrava en el campo de la medicina satisfactiva ${ }^{5}$.

En la actualidad, esta cuestión ha sido reiterada en los pronunciamientos de los tribunales más recientes. En este sentido, el Tribunal Supremo ${ }^{6}$ ha sido muy explícito al precisar que "los efectos que origina la falta de información están especialmente vinculados a la clase de intervención: necesaria o asistencial, voluntaria o satisfactiva, teniendo en cuenta las evidentes distinciones que la jurisprudencia de esta Sala ha introducido en orden a la información que se debe procurar al paciente, más rigurosa en la segunda que en la primera, dada la necesidad de evitar que se silencien los riesgos excepcionales ante cuyo conocimiento el paciente podría sustraerse a una intervención innecesaria o de una necesidad relativa". Es por ello que, ante todo y en síntesis, es conveniente tener presente que en materia de información, el contenido que debe ser transmitido presenta distintos grados de exigencia según se trate de actos médicos realizados con carácter curativo o se trate de la llamada medicina voluntaria porque en cualquier caso, esa variación de contenido debe ser transmitido para que el consentimiento del paciente sea emitido válidamente, es decir, de forma libre, consciente y voluntaria..

\section{BIBLIOGRAFÍA}

1. Andreu Tena E, Azparren Lucas A, Donat Laporta E, Estudio jurisprudencial en medicina satisfactiva. Rev Esp Med Legal. 2013;39(4):163.

2. Sentencia del Tribunal Supremo de 3 de Octubre de 2000 (RJ 2000/7799).

3. Sentencia del Tribunal Supremo de 27 de Abril de 2007 (RJ 2007/3541)

4. Sentencia del Tribunal Supremo de 21 de Octubre de 2005 (RJ 2005/ 118547).

5. Sentencias del Tribunal Supremo de 21 de octubre de 2005 (RJ 2005/ 118547), de 17 de abril de 2007 (RJ 2007/3541).

6. Sentencia del Tribunal Supremo de 16 de Enero de 2012 (RJ 2012/1784).

\section{María Blasco Igual}

Universitat de València. Departament de

Fisioteràpia. Valencia (España).

Correo electrónico: M.clara.blasco@uv.es 